\title{
Edge-coupled membrane terahertz photonic transmitters based on metal-semiconductor-metal traveling-wave photodetectors
}

\author{
Jin-Wei Shi, Shi-Wei Chu, and Ming-Chun Tien \\ Graduate Institute of Electro-Optical Engineering, National Taiwan University, Taipei 10617, \\ Taiwan, Republic of China \\ Chi-Kuang Sun ${ }^{\text {a) }}$ \\ Graduate Institute of Electro-Optical Engineering and Department of Electrical Engineering, \\ National Taiwan University, Taipei 10617, Taiwan, Republic of China \\ Yi-Jen Chiu and John E. Bowers \\ Department of Electrical and Computer Engineering, University of California, Santa Barbara, \\ Santa Barbara, California 93106-5050
}

(Received 19 August 2002; accepted 5 November 2002)

\begin{abstract}
Ultra-high-speed photodetectors and printed-circuit antennas construct photonic transmitters. In this letter, we demonstrate a terahertz $(\mathrm{THz})$ photonic transmitter: edge-coupled membrane photonic transmitters based on metal-semiconductor-metal traveling-wave photodetectors, which are fabricated with low-temperature-grown GaAs photoabsorption layers. With a membrane-based and edge-coupled structure, the demonstrated photonic transmitters can eliminate the requirement of $\mathrm{Si}$ lenses and attain an over 20 times higher optical-to-THz power conversion efficiency $2 \times 10^{-4}$ than vertical illuminated photonic transmitters with Si lenses at the same operation frequency. (C) 2002 American Institute of Physics. [DOI: 10.1063/1.1533846]
\end{abstract}

Photonic transmitters are composed of ultra-high-speed photodetectrs (PDs) and printed-circuit antennas. ${ }^{1}$ Under optical excitations with high-repetition-rate $(\mathrm{GHz}-\mathrm{THz})$ modelocked laser diodes ${ }^{2,3}$ or heterodyne-mixed continuous-wave (cw) laser diodes, ${ }^{4}$ photonic transmitters can radiate highfrequency electromagnetic waves. Low-temperature-grown (LTG) GaAs-based photonic transmitters attract lots of attentions due to their ability to operate in the $\mathrm{THz}$ frequency regime (corresponding to $100-1000 \mu \mathrm{m}$ optical wavelength), which lies beyond the capabilities of both solid-state lasers on the short-wavelength side and of electronic sources such as Gunn or IMPATT diodes ${ }^{5}$ on the long-wavelength side. Compared with other millimeter- or submillimeter-wave emission techniques such as Gunn diodes, ${ }^{5} p$-type Ge-based or quantum-cascade THz lasers, ${ }^{6,7}$ and resonant tunneling diodes, ${ }^{8}$ photonic transmitters have the advantages of simplicity, compactness, wide tunability, and room-temperature operation capability. The demonstrated LTG-GaAs-based photonic transmitters have been applied in $\mathrm{THz}$ image systems and $\mathrm{THz}$ spectrometers. ${ }^{9,10}$ There are two main trends in the advance of photonic transmitters: ${ }^{11,12}$ improving optical-to-THz power conversion efficiency and obtaining high radiation power. Achieving higher conversion efficiency plays a key role in the integration of photonic transmitter systems. High-conversion-efficiency photonic transmitters relieve the power burden imposed on excitation semiconductor lasers. By utilizing the heterodyne mixing technique with $\mathrm{cw}$ lasers, the state-of-the-art LTG-GaAs-based verticalilluminated photomixer with an optical resonant cavity and a resonant twin-dipole antenna structure demonstrated conver-

\footnotetext{
a) Author to whom correspondence should be addressed; electronic mail: sun@cc.ee.ntu.edu.tw
}

sion efficiencies around $3.3 \times 10^{-5}$ and $9 \times 10^{-6}$ at $850 \mathrm{GHz}$ and $1.6 \mathrm{THz}$, respectively. ${ }^{12,13}$ Adopting high-conversionefficiency edge-coupled ultra-high-speed photodetectors should further improve the bandwidth-efficiency product as well as the conversion efficiency of photonic transmitters. ${ }^{11,12}$ However, the previously demonstrated edge-coupled $\mathrm{THz}$ distributed photomixers exhibited much lower conversion efficiency than the vertical-illuminated photomixers. ${ }^{14}$

In this letter, we demonstrate a LTG-GaAs-based THz photonic transmitter, which is composed of an edge-coupled metal-semiconductor-metal (MSM) traveling-wave photodetector (TWPD) (Refs. 15-17) and a co-planar-waveguide (CPW) fed slot antenna. ${ }^{18}$ By utilizing a membrane antenna structure and taking advantage of the superior fully distributed microwave guiding property in MSM TWPDs, highoptical-to-THz-power conversion efficiency $\left(\sim 2 \times 10^{-4}\right)$ can be achieved by testing the photonic transmitter under pulsed operation condition at a $1.6 \mathrm{THz}$ frequency without using Si lenses.

The top view of the demonstrated device is shown in Fig. 1. We adopt a CPW fed slot antenna in our demonstrated device because it can generate higher power than the spiral antenna in the designed resonant frequency ${ }^{4}$ and can be easily integrated with the MSM TWPD, which has a CPW structure to support the photoexcited microwave-guiding mode. ${ }^{15-17}$ A quarter-wavelength impedance transformer is placed between the CPW fed slot antenna and the MSM TWPD for impedance matching. This impedance matching stub is important for a maximum electrical power transfer from the TWPD to the antennas. The radio-frequency (rf) isolation bias tee, which acts as an inductance, ${ }^{19}$ avoids the high-frequency ac current (with a resonant frequency of the slot line antenna) leaking into the dc probe pad. Comparing 


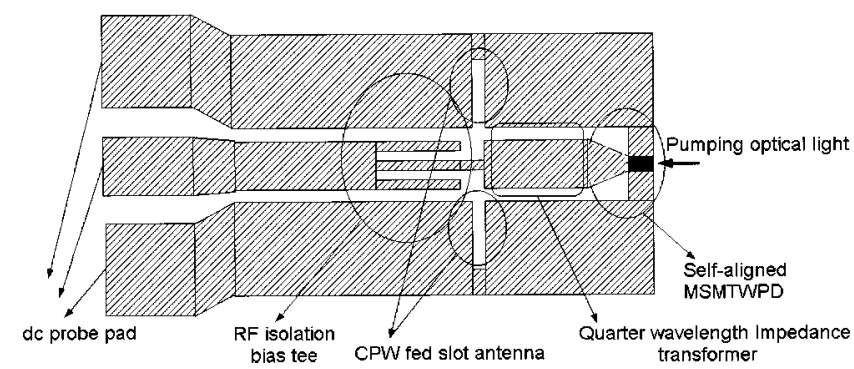

FIG. 1. Schematic diagram (top view) of the demonstrated $\mathrm{THz}$ photonic transmitter

our active photoabsorption region with that of the previous edge-coupled distributed photomixer, ${ }^{14}$ the optical scattering loss between adjacent distributed active regions can be avoided with our demonstrated structure. Another advantage is that the electrical bandwidth of our fully distributed MSM TWPD will not be limited by the Bragg cutoff frequency. ${ }^{20}$ The detailed fabrication processes of our demonstrated device are almost identical to that of the self-aligned MSM TWPDs and are given in Ref. 15. For most photomixers operating in millimeter- and submillimeter-wavelength regimes, Si lenses are required for improving the antenna radiation efficiency from substrates. ${ }^{21}$ However, this integration will increase the cost of packaging. In addition, the long distance between the center (where the antenna should be) and the edge (where the photodetector edge should be) of the available Si lens is also an obstacle for the edge-coupled input optical beam. In order to overcome this problem, we use a membrane structure in our demonstrated edge-coupled $\mathrm{THz}$ photonic transmitters. We removed the GaAs substrate and mounted the membrane of the fabricated device on a glass substrate, which has a much lower dielectric constant than the GaAs layer and can thus allow the radiation of $\mathrm{THz}$ energy into the substrate or free space more easily. ${ }^{21}$ This technique has been adopted in the packaging of ultra-highspeed photodetectors for mass production purposes. ${ }^{22}$ The geometric sizes of the measured devices are given in Table I, which has been used to simulate the frequency response of the $S_{11}$ parameter of this demonstrated structure. ${ }^{23}$ The simulation results show a resonant frequency near $1.6 \mathrm{THz}$ due to the resonant CPW fed slot antenna.

In order to measure the device performance, we used a mode-locked Ti:sapphire laser with a repetition rate of 82 $\mathrm{MHz}$. By passing the broadband femtosecond optical pulses through étalons, we can increase the repetition rate of the light source and trigger the photonic transmitters by coupling this high-repetition-rate light into the edge-coupled MSM TWPD. We used microscope cover glasses with double-sided silver coating as the étalon filters. The thickness of the étalons determines the optical longitudinal mode spacing and repetition rate of the optical pulse train. Some mode-locked semiconductor lasers also use a similar principle to increase the repetition rate to the $\mathrm{THz}$ frequency regime by means of intracavity reflectors. ${ }^{2}$ The étalons that we fabricated have four different resonant frequencies, which are $490 \mathrm{GHz}, 670$ $\mathrm{GHz}, 1.1 \mathrm{THz}$, and $1.6 \mathrm{THz}$. Take the Ti:sapphire spectrum after the $1.6 \mathrm{THz}$ étalon, for example, which is shown as an inset of Fig. 2, the free spectral range of this étalon filter is found to be $\sim 3.2 \mathrm{~nm}$ with a full width at half maximum
TABLE I. Geometric sizes of the demonstrated THz photonic transmitter.

\begin{tabular}{|c|c|}
\hline & Geometric size \\
\hline $\begin{array}{l}\text { Center strip and air gap widths in } \\
\text { the MSM TWPD active region }\end{array}$ & $2 \mu \mathrm{m} / 0.3 \mu \mathrm{m}$ \\
\hline MSM TWPD length & $20 \mu \mathrm{m}$ \\
\hline $\begin{array}{c}\text { Gap width of CPW fed slot line } \\
\text { antenna }\end{array}$ & $2 \mu \mathrm{m}$ \\
\hline $\begin{array}{c}\text { Total length of CPW fed slot line } \\
\text { antenna }\end{array}$ & $70 \mu \mathrm{m}$ \\
\hline $\begin{array}{l}\text { Center strip and air gap widths of the } \\
\text { impedance transformer }\end{array}$ & $10 \mu \mathrm{m} / 7 \mu \mathrm{m}$ \\
\hline Impedance transformer length & $35 \mu \mathrm{m}$ \\
\hline $\begin{array}{c}\text { Width and length of rf isolation } \\
\text { bias tee fingers }\end{array}$ & $2 \mu \mathrm{m} / 35 \mu \mathrm{m}$ \\
\hline $\begin{array}{l}\text { Total thickness of GaAs-based } \\
\text { epilayer and glass substrate }\end{array}$ & $5 \mu \mathrm{m} / 1 \mathrm{~mm}$ \\
\hline Metal (Ti/Au) thickness & $1 \mu \mathrm{m}$ \\
\hline
\end{tabular}

(FWHM) of the transmission peaks $\sim 1.3 \mathrm{~nm}$. The FWHM of the transmission peaks implies that the time domain FWHM of the generated optical pulse train envelope is around $\sim 1$ ps. We used two parabolic mirrors to collimate and focus the radiated $\mathrm{THz}$ pulse onto a liquid-helium-cooled Si bolometer for power measurement. We modulated the excitation optical beam with a mechanical chopper and connected the output electrical signal of the bolometer to a lock-in amplifier to improve the signal/noise ratio. The responsivity of the $\mathrm{Si}$ bolometer was calibrated with a blackbody radiation source. $^{4,12}$ The $\mathrm{THz}$ beam propagation loss in air was also measured and calibrated by measuring the $\mathrm{THz}$ power as a function of distance. For example, the obtained propagation loss at $1.6 \mathrm{THz}$ is about $\sim 17.1 \mathrm{~dB} / \mathrm{m}$.

Figure 2 shows the normalized $\mathrm{THz}$ power radiated from the photonic transmitter at four different operation frequencies under the same operation condition. We excited the device with the same optical average power under a fixed dc bias voltage. We can observe that under the $1.6 \mathrm{THz}$ operation condition the demonstrated device exhibits the highest $\mathrm{THz}$ output power. This measurement result is consistent with the antenna simulation result, ${ }^{23}$ as discussed before. Figure 3 shows the measured bias-dependent output power

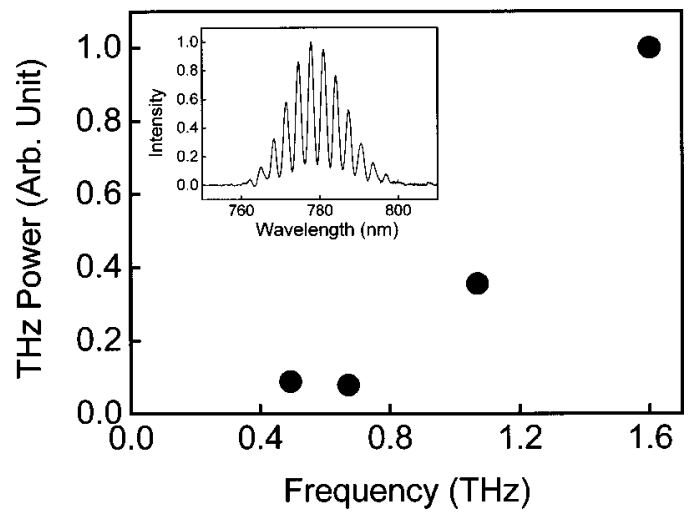

FIG. 2. Measured THz power at four different operation frequencies. Inset shows the measured optical spectrum after a $1.6 \mathrm{THz}$ étalon filter. 


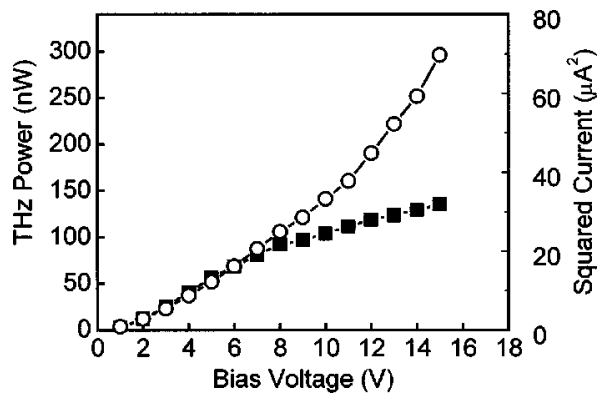

FIG. 3. Measured THz output power (solid square) and squared photocurrents (open circle) vs bias voltage under a fixed optical excitation power of $0.66 \mathrm{~mW}$.

(solid square) at the $1.6 \mathrm{THz}$ frequency after considering the propagation loss under a fixed optical power excitation $(0.66$ $\mathrm{mW})$. High conversion efficiency of $\sim 2 \times 10^{-4}$ between optical excitation power (before coupling into the MSM TWPD) and collected $\mathrm{THz}$ radiation power are achieved at a $15 \mathrm{~V}$ dc bias voltage. The obtained $135 \mathrm{nW}$ average $\mathrm{THz}$ power corresponds to a peak $\mathrm{THz}$ power of $1.6 \mathrm{~mW}$. In our measurement setup, we collected only the radiated power from the glass substrate side, thus even higher output power and conversion efficiencies can be expected if we can also collect the $\mathrm{THz}$ radiation from the free-space side. We neglected the $\mathrm{THz}$ power contribution from high harmonic frequencies $(3.2 \mathrm{THz}, 4.8 \mathrm{THz}$, etc.) because of the electrical bandwidth limitation in MSM TWPD (less than $1 \mathrm{THz}$ ) and the bandwidth $(100 \mathrm{GHz}-3 \mathrm{THz})$ of a $\mathrm{THz}$ filter inside the $\mathrm{Si}$ bolometer. The obtained conversion efficiency is much higher than the previously reported values ${ }^{12,13}$ and can be attributed to the improved bandwidth-efficiency performances of the adopted LTG-GaAs-based MSM TWPDs than the vertical-illuminated LTG-GaAs based PDs. ${ }^{15}$ The measured $\mathrm{THz}$ power from photomixers exhibits a near-quadric dependency on the applied bias voltage and excitation optical power, ${ }^{12}$ thus higher conversion efficiency along with higher radiated power than the values shown in Fig. 3 can be expected with increased optical pumping power and dc bias voltage. The above demonstrated maximum radiation power and conversion efficiency of this device is limited by the damage threshold of the étalon filters, instead of the bandwidth degradation or thermal heating problems of this device. ${ }^{12}$ We square the measured bias-dependent photocurrents (open circles, Fig. 3) and compare them to the biasdependent $\mathrm{THz}$ output power in Fig. 3. It can be observed that the radiated $\mathrm{THz}$ power is proportional to the squared photocurrents when the bias voltage is below $7 \mathrm{~V}$. However, under high dc bias voltages $(8-15 \mathrm{~V})$, the radiated $\mathrm{THz}$ power starts to saturate. We attribute this phenomenon to the lifetime increasing effect in LTG-GaAs-based PDs under high bias voltages. ${ }^{12,16}$ Carrier lifetime increase implies electrical bandwidth degradation and output power degradation in the $\mathrm{THz}$ frequency regime.

In conclusion, by using the edge-coupled MSM TWPD with superior microwave guiding properties, we demonstrate a membrane $\mathrm{THz}$ photonic transmitter without $\mathrm{Si}$ lenses and attain a high-optical-to- $\mathrm{THz}$ power conversion efficiency (2 $\times 10^{-4}$ ) under a pulsed operation condition. The maximum $\mathrm{THz}$ radiation power and the optical-to- $\mathrm{THz}$ conversion efficiency were limited by the maximum allowable optical power transmitted after the étalon filters. The edge-coupled structure and high-conversion-efficiency characteristic of our demonstrated devices are suitable for monolithic integration with a mode-locked semiconductor laser with high repetition rate or a two-wavelength $\mathrm{cw}$ diode laser. The integrated device can act as a compact, all-solid-state, and tunable $\mathrm{THz}$ radiation source.

This work is sponsored by the National Science Council of Taiwan, under NSC91-2215-E-002-021 and NSC91-2112M-002-050, and partially sponsored by Institute of Applied Science and Engineering Reserach, Academia Sinica, Taiwan.

${ }^{1}$ T. Nagatsuma, M. Shinagawa, N. Sahri, A. Sasaki, Y. Royter, and A. Hirata, IEEE Trans. Microwave Theory Tech. 49, 1831 (2001).

${ }^{2}$ D. A. Yanson, M. W. Street, S. D. McDougall, I. G. Thayne, J. H. Marsh, and E. A. Avrutin, Proceedings of the 2001 International Topical Meeting on Microwave Photonics Technical Digest (2002), p. 25.

${ }^{3}$ S. Arahira, Y. Matsui, and Y. Ogawa, IEEE J. Quantum Electron. 32, 1211 (1996)

${ }^{4}$ S. Verghese, K. A. McIntosh, and E. R. Brown, IEEE Trans. Microwave Theory Tech. 45, 1301 (1997).

${ }^{5}$ H. Eisele, A. Rydberg, and G. I. Haddad, IEEE Trans. Microwave Theory Tech. 48, 626 (2000).

${ }^{6}$ Yu. P. Gousev, I. V. Altukhov, K. A. Korolev, V. P. Sinis, M. S. Kagan, E. E. Haller, M. A. Odnoblyudov, I. N. Yassievich, and K.-A. Chao, Appl. Phys. Lett. 75, 757 (1999).

${ }^{7}$ R. Kohler, A. Tredicucci, F. Beltram, H. E. Beere, E. H. Linfield, A. G. Davies, D. A. Ritchie, R. C. Iotti, and F. Rossi, Proceedings of the Conference on Lasers and Electro-Optics (CLEO), OSA, postdeadline papers, CPDC 12-1 (2002).

${ }^{8}$ M. Reddy, S. C. Martin, A. C. Molnar, R. E. Muller, R. P. Smith, P. H. Siegel, M. J. Mondry, M. J. W. Rodwell, H. Kroemer, and S. J. Allen, Jr., IEEE Electron Device Lett. 18, 218 (1997).

${ }^{9}$ K. J. Siebert, H. Quast, R. Leonhardt, T. Loffler, M. Thomson, and S. Czasch, Appl. Phys. Lett. 80, 3003 (2002).

${ }^{10}$ C. Pin, G. A. Blake, M. C. Gaidis, E. R. Brown, K. A. McIntosh, S. Y. Chou, M. I. Nathan, and F. Williamson, Appl. Phys. Lett. 71, 1601 (1997).

${ }^{11}$ K. Kato, IEEE Trans. Microwave Theory Tech. 47, 1265 (1999).

${ }^{12}$ A. W. Jackson, Ph.D. thesis, University of California at Santa Barbara (1999)

${ }^{13}$ S. M. Duffy, S. Verghese, K. A. McIntosh, A. Jackson, A. C. Gossard, and S. Matsuura, IEEE Trans. Microwave Theory Tech. 49, 1032 (2001).

${ }^{14}$ E. K. Duerr, K. A. McIntosh, S. Verghese, Proceedings of the Conference on Lasers and Electro-Optics (CLEO), OSA Technical Digest (2000), p. 382.

${ }^{15}$ J.-W. Shi, K. G. Gan, Y. J. Chiu, Y.-H. Chen, C.-K. Sun, Y. J. Yang, and J. E. Bowers, IEEE Photonics Technol. Lett. 13, 623 (2001).

${ }^{16}$ K. G. Gan, J.-W. Shi, Y.-H. Chen, C.-K. Sun, Y. J. Chiu, and J. E. Bowers, Appl. Phys. Lett. 80, 4054 (2002).

${ }^{17}$ J.-W. Shi, K. G. Gan, Y.-H. Chen, C.-K. Sun, Y. J. Chiu, and J. E. Bowers, IEEE Photonics Technol. Lett. 14, 1587 (2002).

${ }^{18}$ B. K. Kormanyos, W. Harokopus, Jr., Linda P. B. Katehi, and G. M. Rebeiz, IEEE Trans. Microwave Theory Tech. 42, 541 (1994).

${ }^{19}$ K. C. Gupta, R. Garg, I. Bahl, and P. Bhartia, Microstrip Lines and Slotlines, (Artech House, Boston, MA, 1996).

${ }^{20}$ T. T. Wong, Fundamental of Distributed Amplification (Artech House, Boston, MA, 1993).

${ }^{21}$ D. B. Rutledge, D. P. Neikirk, and D. P. Kasilingam, Proceedings of the Conference on Infrared and Millimeter Waves (1983), Vol. 10.

${ }^{22}$ Y. Royter, T. Furuta, S. Kodama, N. Sahri, T. Nagatsuma, and T. Ishibashi, IEEE Electron Device Lett. 21, 158 (2000).

${ }^{23}$ Zeland Software, Inc. IE3D, Taipei, Taiwan. 
Applied Physics Letters is copyrighted by the American Institute of Physics (AIP). Redistribution of journal material is subject to the AIP online journal license and/or AIP copyright. For more information, see http:/ojps.aip.org/aplo/aplcr.jsp

Copyright of Applied Physics Letters is the property of American Institute of Physics and its content may not be copied or emailed to multiple sites or posted to a listserv without the copyright holder's express written permission. However, users may print, download, or email articles for individual use. 